\title{
Peñas, canción de protesta y transformación política en Chile (1965- 1973)
}

\begin{abstract}
ARIEL HERNÁN MAMANI*
RESUMEN: El presente artículo busca estudiar las peñas folclóricas que florecieron a mediados de la década del 60 en Chile. Estos espacios funcionaron como centros de sociabilidad en locales donde se presentaban números musicales en vivo. Con la asistencia de un público numeroso pero sin llegar a ser masivo se transformaron en sitios donde la discusión política e ideológica también se hizo presente. A su vez resultaron los primeros ámbitos en dar acogida a un movimiento musical que alcanzó relevancia mundial: la Nueva Canción Chilena. El intento es demostrar como las peñas folclóricas fueron un importante centro de discusión y transformación politica con una importante tarea de irradiación ideológica y cultural a partir de la práctica musical.
\end{abstract}

PALABRAS CLAVE: Peñas; Sociabilidad; Cantautor; Política; Nueva Canción Chilena.

\section{Peñas, political song and social change in Chile (1965-1973)}

\begin{abstract}
This paper makes a study of the folk clubs (called "peñas") appeared in the middle of the 1960s in Chile. They were spaces that functioned as centers of sociability where musical numbers were presented live. At the same time they were transformed into sites where political and ideological discussion was also present. In turn, these spaces were the first areas to host a musical movement that reached global significance: the New Chilean Song. It will seek to demonstrate how the "peñas" were an important focus of discussion and political transformation with an important task of ideological and cultural irradiation from musical practice.
\end{abstract}

KEYWORDS: Peñas; Sociability; Songwriter; Politics; New Chilean Song.

\footnotetext{
* Ariel Hernán Mamani es Historiador argentino egresado de la Universidad Nacional de Rosario (UNR), donde se desempeña actualmente como profesor de Historia de América. Además es Profesor de Historia Americana en la Universidad Autónoma de Entre Ríos (UADER). Ha concentrado su trabajo en el estudio de los vínculos existentes entre música, cultura y política en la $2^{\mathrm{a}}$ mitad del siglo XX. A su vez se ha dedicado al análisis de la producción de artefactos culturales que constituyen relatos sobre el pasado y conforman discursos historiográficos no tradicionales. E-mail: mamaniariel@yahoo.com.ar
} 


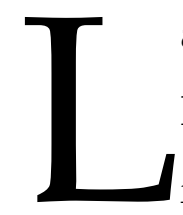

a década del 60 significó una radical transformación de las costumbres de los habitantes de las grandes urbes, no quedando al margen las diferentes formas de entretenimiento, diversión y sociabilidad, lo que llevó a un importante quiebre con la tradicional forma de apropiación del espacio público y sus posibles combinaciones con el ámbito de la vida privada (GONZÁLEZ, ROLLE y OLSHEN, 2009). En este contexto, las peñas folclóricas fueron un fenómeno que hizo explosión en las principales ciudades chilenas a mediados de la década del '60. Funcionaron en locales donde se presentaban números musicales en vivo y representaron un importante ámbito de sociabilidad, con la asistencia de un público numeroso pero no masivo. Las actividades desarrolladas se vincularon al ámbito musical pero sin cerrarse a otras manifestaciones artísticas que encontraron también allí su sitio. Estos espacios albergaron a una amplia gama de cantautores de la canción protesta, en boga por aquellos años, como así también a agrupaciones folclóricas de corte más tradicional. La discusión política también se dio cita en las peñas y junto a la música fueron un elemento central que dotó de identidad cultural a gran parte de los concurrentes.

Muchos de estos sitios eran precarios y contaban apenas con una pobre iluminación. Sin ventilación, con inestables instalaciones, asistir a las presentaciones en estos locales era casi un acto militante en sí mismo, aunque también cierto snobismo pareció impulsar a muchos de los asistentes. Algunos otros, en una apuesta más comercial, poseían infraestructura más confortable y se esmeraban en la atención de los concurrentes.

El intento es aquí el de realizar un racconto de las diferentes experiencias a las que genéricamente denominaremos peñas dentro del ámbito urbano chileno en la década del 60. No todas asumieron un mismo formato, algunas fueron itinerantes, otras solo se realizaron en ocasiones especiales, mientras que solo algunas prolongaron su existencia por muchos años. Muchas estuvieron reñidas con los cánones de comercialización, mientras que otras vislumbraron en ello su plena realización. El análisis de estos sitios no pretende abarcar a la totalidad de ellos, sino más bien a un reducido grupo, que bien por afinidad o bien por oposición, son interesantes para ejemplificar en general el funcionamiento y las principales 
características de estos locales. Se intentará aquí estudiar el funcionamiento interno de dichos locales, el perfil de los asistentes, la variedad, cantidad y características de los artistas participantes. Por lo demás se pretende establecer las posibles relaciones entre los diversos espacios, así como también que grado de componente ideológico se puede hallar presente en cada una de las peñas analizadas. En algunos casos el acercamiento será apenas tangencial, mientras que en otros se ahondará todo lo posible.

\section{Folclore y cultura de masas}

Las manifestaciones de carácter popular fueron incrementando su visibilidad durante el siglo XX de la mano de una industria cultural cada vez más presente en la vida cotidiana. Esta penetración de la sociedad en su conjunto, por parte de los saberes populares, facilitó la expansión de lo que comúnmente se denominó cultura de masas, y cuyo impulso se vio estimulado por la producción y reproducción de artefactos culturales a través de medios técnicos y de su incansable búsqueda para captar públicos cada vez más masivos. Es por eso que el desarrollo tecnológico y social que la industria musical alcanzó hacia mediados del siglo XX, otorgó a la música popular una visibilidad raramente conseguida hasta ese momento. Sin embargo no todas las puertas se abrieron de igual forma para estas manifestaciones.

La música predominante en los medios masivos de comunicación en Chile a mediados de la década del 50 era mayoritariamente extranjera. Por un lado la música argentina, tanto la de raíz folclórica como el tango, gozaba de un interesante campo de difusión; y por el otro la música mexicana tenía una amplia propagación, en especial en el ámbito rural. Pero en los espacios urbanos la música de origen anglosajón reinaba, tanto en sus versiones originales como en las numerosas imitaciones vernáculas. Carmen Oviedo plantea que la música de carácter folclórico, a fines de la década del '50, se encontraba en franca desventaja en relación a los ritmos extranjeros. 
(...) el folklore parecía haber perdido la batalla frente a los ritmos extranjeros. Para estar a la moda había que cantar en inglés y las pocas manifestaciones de lo tradicional que persistían, se enmarcaban en arquetipos de escasa representatividad que ciertas personas, o grupos de personas de gran influencia, sobre todo económica, se esforzaban por mantener (OVIEDO, 1991, p. 79).

Unas pocas manifestaciones musicales de carácter folclórico chileno podían encontrarse en ese mar de sonidos foráneos, aunque fuertemente arraigadas a modelos, que a principios de los años 60 poco representaban a numerosos sectores urbanos. Nacidas al amparo de la modernización producida en la década del '20, producto de la masiva inmigración de trabajadores rurales a las ciudades, las manifestaciones folclóricas habían sufrido un fuerte proceso de transformación, adaptándose a los designios del mercado discográfico y a los gustos urbanos, generando un producto que, más que la recuperación genuina de los saberes tradicionales del mundo rural chileno, lo que se proyectaba era la caricatura que los sectores urbanos trazaban de ese mundo bucólico e idílico que representaba para ellos el espacio rural.

La búsqueda de una música de carácter nacional había hallado anclaje en el imaginario rural de tipo hacendal, cuya figura emblemática era el huaso (GONZÁLEZ; ROLLE 2004). ${ }^{1}$ De esta manera la imagen del huaso, a partir de la transformación de la tonada y la cueca en paradigmas sonoros de carácter nacional, se transfiguró en el modelo identitario de Chile, encontrando en el mundo rural ese enlace y esa continuidad con el pasado, siempre necesaria para ese tipo de construcciones. Esta tentativa ensayada de erigir el imaginario nacional teniendo como referente al mundo campesino poseía un amplio grado de arbitrariedad puesto que “(...) Chile no es un país eminentemente campesino ni su economía reposa sobre los resortes del agro (...)" (MANNS, 1986, p. 42), sin embargo la importancia de la zona central parece haber inclinado la balanza con su fuerte impronta rural en la conformación de dicho imaginario.

Durante todo el siglo XIX Chile siguió siendo un territorio de grandes haciendas, la propiedad de las cuales confería status social, influencia política (si era deseada) y

\footnotetext{
${ }^{1}$ Se denomina así al personaje típico de la zona rural del centro y sur de Chile. Un uso generalizado del término refiere, en particular, a los sectores más acomodados del campo chileno, que se caracterizan por su apego a las tradiciones rurales y fuertemente reactivos hacia lo que encarna la vida citadina y moderna.

MAMANI, Ariel Hernán. Peñas, canción de protesta y transformación política en Chile (1965-1973). Música Popular em Revista, Campinas, ano 1, v. 2, p. 121-47, jan.-jun. 2013.
} 
unos ingresos holgados (...). Esta tradición de terratenientes es una de las claves para entender la historia chilena desde los tiempos coloniales hasta mediados del siglo XX (COLLIER, 1992, p. 250).

A pesar de contar la música folclórica con un circuito de programas radiales, la competencia con la música de origen extranjero parecía ser infructuosa. Por su parte los espacios para las presentaciones en vivo eran marcadamente escasos. Es así como René Largo Farías, importante difusor de la música chilena, se quejaba airadamente luego de haber organizado un festival

Es necesario que, a la brevedad posible, se inicie una difusión folklórica, especialmente en la provincia de Santiago... Sólo mil quinientas personas asistieron al Festival... ¡La gente está intoxicada con ritmos foráneos! (Revista Ecran, 1876, 17/I/1967).

De manera que, salvo honrosas excepciones, el folclore musical chileno era visto por la población como un conjunto de manifestaciones anecdóticas, necesarias para las fiestas patrias, cuando el nivel de difusión llegaba a su cenit, para luego perderse otra vez en el ostracismo.

(...) la relación del gran público con la música folklórica era sumamente superficial y conocía una cierta época de auge durante las festividades patrias. En el mes de septiembre (...) se bailaba cueca y se cantaba la tonada hasta altas horas de la noche. Pero la cosa no pasaba más allá de eso (SANTANDER 1984, p. 29-30).

En los años 60 muchas manifestaciones de la música popular entraron en una fase de formidables transformaciones. A principios de la década surgió un movimiento denominado Nueva Ola que salió a la luz con versiones importadas del ámbito estadounidense y textos generalmente frívolos. En forma casi paralela nació un movimiento denominado NeoFolklore, que logró altísimas cotas de ventas con diferentes agrupaciones y solistas musicales. Según Santander, el neofolklore fue:

(...) la primera manifestación de una profunda renovación en este aspecto de la cultura popular chilena y, entre otras cosas, tuvo el mérito de asimilar algunos aspectos positivos del fenómeno argentino al mismo tiempo que le abría paso a los nuevos creadores (1984, p. 28).

Estas agrupaciones apostaron a una importante serie de innovaciones que los diferenciaron de los conjuntos típicos. Por un lado se modernizaron en gran medida los arreglos vocales, por el otro, 
(...) la mayoría de estos grupos estaba formada por jóvenes que usaban smoking y descartaban la ropa de los huasos de los conjuntos de música típica. Tomaban, así, una cierta distancia de la cultura rural al no asumirse como portadores de esta tradición, (...). También se alteró la temática de las canciones (COSTA GARCÍA, 2009, p. 23).

Por otro lado, aún con algunos puntos de contacto con el NeoFolklore, se desarrolló un movimiento que tendría fuerte impacto y alcanzaría relieve mundial: la Nueva Canción Chilena (NCCh) y cuyos principales exponentes fueron Víctor Jara, Patricio Manns, Ángel Parra, y los conjuntos Quilapayún e Inti-Illimani. Este movimiento no renegó de sus posiciones políticas, y por lo tanto dejó su impronta más allá de lo estrictamente artístico.

Esta línea de "compromiso" o de "protesta" sería una de las principales características - si no la principal - que diferencia a la Nueva Canción Chilena de las tendencias previas, paralelas o posteriores. Y esta misma cualidad conduciría irrevocablemente al empleo de interpretaciones vocales que convinieran mejor al sentido de los textos, y que contrastaran fuertemente con la agógica usualmente utilizada (ADVIS, 2012, p. 34).

La mayoría de los representantes de este prolífico movimiento musical adhirieron a las ideas de izquierda, y si bien alcanzaron altos niveles de creatividad y refinamiento estético, se los relaciona comúnmente con la participación y el compromiso político. Sin embargo, los primeros pasos de la NCCh estuvieron lejos de los canales de difusión, teniendo que buscar alternativas para presentar sus propuestas.

\section{En busca de un sitio para la canción comprometida}

Los hermanos Parra, Isabel y Ángel, retornaron a Chile desde Europa en 1964 para participar en la campaña presidencial apoyando al candidato del Frente de Acción Popular (FRAP), Salvador Allende. Esta elección era vista por la izquierda como una posibilidad concreta de acceder al poder, ya que 4 años antes Allende había perdido la elección por un estrecho margen de votos. Sin embargo, esta vez la derrota fue más amplia, y triunfó el democristiano Eduardo Frei Moltalva. A pesar de ello, los hermanos Parra no retornaron a Francia, sino que permanecieron en Chile, donde encontraron una serie de dificultades para insertarse en el medio 
artístico. Como ya se mencionó, la música folclórica poseía una presencia menor en los medios, particularmente aquella cuyo contenido podía vincularse abiertamente con la canción protesta. Los medios masivos no veían con buenos ojos la politización a la que se acercaba la música, desdeñando toda producción artística que asumiera un compromiso explícito.

De regreso de Europa, - rememora Ángel - fuimos al 'Pollo Dorado' y otros locales
nocturnos a pedir trabajo. Por supuesto que no nos contrataban, porque yo andaba
con los mismos eternos pantalones de cuero, no tenía traje de huaso con manta y
espuelas, y a ellos no les servían nuestras canciones folclóricas auténticas, ni menos
las canciones políticas (VARAS; GONZÁLEZ, 2005, p. 79).

Además de la dificultad de insertarse en los locales que podían brindarles algún sustento y divulgación, Ángel e Isabel Parra se encontraron con la “(...) indiferencia de los medios de comunicación, que seguían entusiasmados con el rock norteamericano y poco caso hacían de lo que pudiera oler a folklore" (SANTANDER, 1984, p. 28). Más bien habría que aclarar que lo que realmente costaba asimilar a una parte de la sociedad era el abandono del estereotipo folclórico consolidado en las décadas del 30 y 40, es decir aquella música reputada como típica cuyo arquetipo representativo eran los conjuntos de huasos. Esta música considerada como legítima era (...) la canción que se canta - denunciaba Patricio Manns - en todas las fiestas, urbanas o rurales, la canción que ensaya el coro del colegio, la canción que el político o dirigente progresista quieren oír en su sobremesa, la canción que arrulla la embriaguez del minero o del pescador (MANNS, 1986, p. 46). De ese modo, los grupos folclóricos que gozaban de una amplia difusión - continuaba Manns (1986, p. 46): “(...) cantaran al campo chileno, al paisaje, a la nostalgia del arroyo, a la china de trenzas, a la tranquera, a la vieja casa de campo (la casa patronal)".

Ante ese panorama los hermanos Parra debieron buscar alternativas laborales, como por ejemplo cuando en televisión "entre un anuncio comercial y otro cantaban en un espectáculo patrocinado por una famosa marca de sales hepáticas" (JARA, 2009, p. 207). Asimismo, los espacios que posibilitaran la presentación de números folclóricos, como teatros o locales nocturnos, era inexistente para un tipo de música comprometida y alejada de los estereotipos. “(...) no había - señala Santander - en esa época ningún lugar especial donde estos cantautores pudieran mostrar sus 
creaciones" (1984, p. 28). Es por ello que los hermanos Parra buscaron recrear en algún sentido a las boîtes de nuit parisinas, aquellos locales del barrio latino donde habían actuado junto a su madre, la folclorista Violeta Parra durante su estadía europea.

La oportunidad se dio en 1965, cuando Ángel quedó al cuidado de la casa del cantante y artista plástico Juan Capra, quien se había trasladado a Europa. De manera que transformó esa vieja casona, ubicada en Carmen $\mathrm{N}^{\circ} 340$, a unas calles del centro de Santiago, en un espacio para poder actuar junto a otros artistas. Es así como en 1965 se inauguró La Peña de los Parra, teniendo como artistas estables al propio Ángel, a su hermana Isabel, a Patricio Manns y a Rolando Alarcón, estos últimos cantautores que tenían ya cierto renombre al estar vinculados al Neofolclore. Al poco tiempo, al pequeño grupo de artistas estables, se sumó el cantante y director de teatro

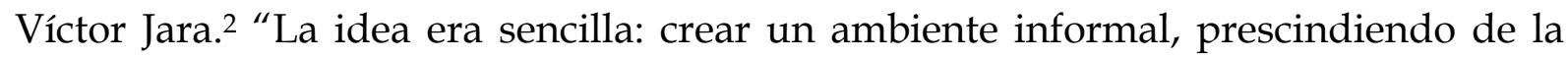
censura y los atavíos comerciales, donde los cantantes folclóricos pudieran aparecer con su ropa de todos los días, actuar e intercambiar canciones e ideas" (JARA, 2009, p. 89).

Todos los músicos estables de La Peña de los Parra cantaban canciones comprometidas políticamente y desarrollaban una militancia de izquierda. Su nivel de compromiso fue evidente desde la apertura misma de la peña, siendo una marca identitaria para el local, dotando de un importante nivel de pertenencia a los asistentes. "Desde el comienzo quedó muy en claro el compromiso político de los artistas de la Peña, pues cantar canciones de denuncia social en nuestro país a mediados de los sesenta era un hecho inédito que provocó una polémica cultural sin precedentes" (SALAS ZÚÑIGA, 2003, p. 66).

El lugar era poco propicio para un espectáculo musical, sin embargo los artistas fueron adaptando ingeniosamente los ambientes para albergar al público, disponer de un improvisado escenario y contar con un mínimo servicio de buffet, que consistía en una empanada de pino y un vaso de vino tinto, al cual el asistente se hacía acreedor una vez abonado el valor de la entrada.

\footnotetext{
2 Este grupo se mantuvo estable durante los primeros años de la peña, y si bien a la postre se fue renovando, se lo asocia principalmente como el núcleo inaugural de la NCCh, cuyo origen está vinculado en forma estrecha con la Peña de los Parra. 
Hay que pagar una entrada de 35 escudos - explicaba Ángel Parra -. Esto les da derecho a un trago de vino y a presenciar el espectáculo. El jueves rebajamos la entrada porque recibimos a los estudiantes. También hacemos funciones gratis a beneficio de distintas obras (AGUILERA, 1972, p. 25).

A medida que la peña fue creciendo el menú se fue ampliando hasta incluir anticuchos, pan casero y mate con malicia (mate con gotas de aguardiente) (JARA, 2009). Para evitar problemas “El vino y las empanadas fueron estrictamente racionados para que los comensales no se entusiasmaran y la fiesta musical no terminara en bataholas incontrolables" (SANTANDER, 1984, p. 30). Esto parecía ser esencial para un proyecto que priorizaba el valor de la palabra en la forma canción y que pretendía tener a la peña como un espacio privilegiado para la audición, la reflexión y la discusión artística y política, una búsqueda bastante alejada de los locales musicales más tradicionales y comerciales.

Los centros donde se acostumbraba presentar el folklore más oficial, eran locales señala Eduardo Carrasco - donde no se iba a escuchar música, sino a comer, a tomar o a bailar. En ellos, el ambiente era de una festividad banal, especiales para una 'despedida de soltero', o una borrachera ramplona, pero imposibles para la presentación de un artista cuyo propósito no fuera hacer relinchar al público. 'AArriba las palmas!' gritaban en estos lugares los huasos de pacotilla, sonriendo desde sus escenarios repletos de banderolas y escarapelas 'patrióticas'. (...) Estas fiestas forzadas terminaban a menudo en bulliciosas parrandas que poco tenían que ver con la música. Era imposible intentar cantar allí (CARRASCO, 2003, p. 64).

Pedro Aceituno, por aquél entonces integrante del grupo musical Curacas, relata que en La Peña de los Parra

(...) nadie hablaba, no se chupaba (sic). Tú pagabas tu entrada, entrabas a una pieza y te daban un vaso de vino caliente, eso era todo. Comenzaba la primera parte del espectáculo que duraba 40 a 50 minutos, donde absolutamente nadie hablaba; se escuchaba al artista, y si algún desubicado llegaba con algunos copetes, con el ánimo de chunga, la gente le tiraba un vaso por la cabeza (...) (BRAVO; GONZÁLEZ 2009, p. 30).

De todas formas, por lo bajo, los asistentes sabían hacer circular bebidas alcohólicas. Con el tiempo el local de los Parra fue ampliando sus instalaciones hasta incluir “(...) altillo, comedores, parrón, sala de discos y tienda de tejidos, salas de estudio e información" - relata Osvaldo Rodríguez (1984, p. 31), demostrando que La Peña de los Parra se transformó en una especie de centro cultural. "Los Parra tienen difusión cultural a todo nivel. Ellos les dan oportunidad a pequeños artesanos para 
vender a mejor precio sus productos. También dictan clases de folklore" (AGUILERA, 1972, p. 25).

Si bien en un principio hubo noches con una escasísima presencia de público, rápidamente se fue "corriendo la voz" y "en cierta época, - relata Patricio Manns - debíamos cumplir cuatro presentaciones por noche para recibir a la gente que se alineaba en la calle durante horas para conseguir el acceso" (1986, p. 65). Joan Jara (2007) atestigua haber asistido por primera vez a La Peña de los Parra a una semana de su inauguración y refiere que el local estaba atestado de gente. Este fenómeno se daba a pesar de no contar con publicidad alguna y de que las instalaciones dejaban mucho que desear. Según Osvaldo Rodríguez “No había calefacción central. Las sillas eran incómodas, la ventilación insuficiente si no se abrían las puertas y si se abrían, el frío viento del invierno lo invadía todo" (1986, p. 61). A su vez, el local no poseía ninguna indicación publicitaria en su exterior. "La entrada era poco atractiva. Si no estabas al tanto, podías pensar que aquello era una destartalada casa particular" (JARA, 2007, p. 89). Sin embargo el éxito fue inmediato, lo que demuestra la necesidad que tenía un amplio sector de la población en contar con ámbitos de estas características, y "lo cierto es que los artistas de nuevo tipo, sostiene Carrasco - que pululaban por todos lados sin encontrar donde presentar sus creaciones, necesitaban de estos nuevos lugares" (2003, p. 63).

Muchos artistas vinculados a la canción protesta se acercaron o actuaron en La Peña de los Parra, como Atahualpa Yupanqui, Mercedes Sosa, Paco Ibáñez, Silvio Rodríguez y Pablo Milanés o Daniel Viglietti (RODRÍGUEZ, 1984). Tanto los artistas como el público identificaban a la peña como un ámbito alternativo, que escapaba a los estrechos marcos de los circuitos estrictamente comerciales y ofreciera una opción al pintoresquismo folclórico de la canción tradicional cultivada por los conjuntos de huasos. Tito Fernández, participante de La Peña de los Parra, manifestaba que

\footnotetext{
Ahí Patricio Manns no tenía necesidad de cantar 'Arriba en la Cordillera' ni yo 'La casa nueva'. Uno iba a ver qué iba a hacer Patricio Manns, qué iba a hacer Ángel Parra y qué iba a hacer Isabel. Uno iba ávido de novedades, no de éxitos de discos (...). Las peñas pertenecían a un mundo de la cultura distinto, que no se basaba en la entrada económica (BRAVO; GONZÁLEZ, 2009, p. 30-31).
} 
Además el repertorio interpretado no hacía concesiones, de manera que las canciones más combativas y cuyo mensaje era explícito tenían allí un sitio asegurado. "La Carta”, “Si somos americanos”, "El pueblo”, “A desalambrar” o "Al centro de la injusticia" eran interpretadas ante un público ávido por escuchar esas canciones. La Peña de los Parra sirvió como un modo de difusión de aquellos artistas que tenían pocas posibilidades de difusión o que encontraban algún obstáculo a la circulación de sus obras.

La estrecha vinculación entre espacio privado y espacio público (en este caso la peña) fue producto de la necesidad propia de los concurrentes, proceso llevado a cabo con el objetivo final de legitimar dichos espacios. En buena medida la peña puede ser pensada como una puesta en público de una práctica privada de amplia difusión en los años 60 como fueron las guitarreadas, especialmente de carácter estudiantil. ${ }^{3}$ Esto asimismo provocó la reproducción social de un perfil cimentado a partir del espacio público como así también el aporte a la construcción que plasmaban los propios asistentes, quienes con sus costumbres, rechazos o aceptación, realizaban una contribución sustancial al perfil que adquiría el espacio.

La casona poseía un par de amplias habitaciones que se habían unido entre sí al ser derribada la pared divisoria y estaban repletas de pequeñas mesitas y bancos de madera algo destartalados e incómodos. En un principio la capacidad fue de unas 200 personas, pero después de la ampliación se llegó a unas 350. La recaudación de cada noche era cuidadosamente repartida a partir de un elemental sistema. Al finalizar los tres días de peña (el local funcionaba jueves, viernes y sábado), la recaudación se dividía en dos. Una de las mitades, a su vez, se repartía en partes iguales entre Ángel e Isabel, quienes mantenían el local; la otra se fraccionaba entre los artistas que habían participado en aquellas noches. Marta Orrego, por aquél entonces pareja de Ángel Parra y colaboradora de la peña, sostiene que: “todo funcionaba con bastante anarquía, pero bien, con mucho respeto humano. No había neurosis, éramos felices" (GODOY, 1985, p. 13).

\footnotetext{
3 Para la amplia difusión que alcanzó la guitarra como instrumento acompañante ver GONZÁLEZ; ROLLE y OLSHEN, 2009, p. 60-72. 
La decoración semejaba a la de un bar portuario, con redes de pescador en los techos, paredes blancas (que poco a poco fueron cubriéndose de los espontáneos mensajes de los concurrentes) y velas sobre botellas de vino, ya que una falsa creencia popular sostenía que así se lograba disipar el humo de los cigarrillos. Las pequeñas sillas, como ya se señaló, no eran muy cómodas, al igual que el resto de las instalaciones. "Apretujado en uno de aquellos incómodos bancos de madera - repasa Joan Jara -, en una atmósfera enrarecida y cargada de humo, tenías que ser realmente muy aficionado para resistir las tres o cuatro horas de música" (JARA, 2007, p. 90).

El escenario no era más que una pequeña plataforma de madera y permitía que los intérpretes estuvieran apenas por encima de los asistentes, lo que acortaba la distancia entre artista y público, generando un ambiente de cercanía e intimidad. "En una esquina, una pequeña tarima, a modo de escenario, con un póster de fondo donde resalta la imagen del Che Guevara. Todo está rodeado de pequeñas mesas y bancas, que no alcanzan a contener el público que habitualmente asiste" (AGUILERA, 1972, p. 25).

En realidad este espacio, a pesar de contar con una buena repercusión de público, no aspiraba a una masividad mucho mayor, tal vez porque lo que se priorizaba era la cercanía del artista con su público, la innovación estética y el debate de ideas. "En general, su estructura se asemeja a la de una casa donde vive una numerosa familia, en la que existe intimidad y confianza" (BRAVO; GONZÁLEZ, 2009, p. 17-18). Este tipo de espacio pequeño, casi íntimo, puso en el centro de la escena al cantautor. ${ }^{4}$ La canción popular intentó cumplir así una función concreta: el paso de la esfera íntima de la escritura personal a la esfera social, en la que se realiza como acto de comunicación (RIMBOT, 2006). De esta manera, el canto en primera persona, recurso ampliamente utilizado, trasladaba la firme voluntad de engendrar una alocución íntegramente asumida. Por otro lado, la presencia de la canción popular en estos ámbitos alcanzó un carácter de fácil circulación y transmisión oral. Allí el artista rescataba ciertos usos tradicionales, a imagen del trovador y del juglar, brindando al público la visión íntima de su tiempo.

\footnotetext{
${ }^{4}$ Se utiliza aquí el término cantautor para referir al músico popular que interpretaba preferentemente canciones de su autoría, donde prevalecían mensajes de crítica social o reflexión de corte filosófico. 
En este sentido se puede argumentar que la Peña de los Parra fue un sitio donde constantemente se producía dicha interacción, ya que como parte de un espacio no privado, tenía dimensiones reducidas, lo que brindaba cercanía entre intérprete y público. Lo despojado de la performance y el alejamiento de las ataduras comerciales le otorgaban un carácter intimista. Esto se articulaba con la apuesta, por parte de los artistas, de intentar establecer vínculos con el auditorio, eliminando barreras y sintiéndose uno parte del otro.

El escenario ha dejado de ser un lugar tabú hasta donde sólo pueden llegar algunos privilegiados. Aquí suben en igualdad de condiciones artistas como Richard Rojas, Rolando Alarcón o Nano Acevedo, y solistas o conjuntos desconocidos, ya sea de Santiago o de alguna provincia lejana (Revista Ramona 32, Junio, 1972, p. 16).

La Peña funcionaba como espacio donde el artista se presentaba en vivo para unos cuantos que quisieran apreciar su arte. La cercanía y lo pequeño del espacio brindaba la posibilidad de que el cantante lograra un ambiente íntimo y cómplice, tanto desde lo vocal como desde lo gestual. Al prescindir de la amplificación, se tornaba esencial el silencio del público. De esta forma es comprensible la insistencia en no servir comidas ni bebidas, con el objetivo preciso de evitar lo que los Parra habían vivido en Europa, “(...) nosotros no queríamos saber nunca más de platos y paellas que pasaran por delante mientras nosotros estábamos cantando" (VARAS; GONZÁLEZ, 2005, p. 79).

El público habitué era heterogéneo, aunque es posible trazar un perfil bastante definido, “(...) políticos, profesionales liberales, elementos progresistas de la burguesía y de la pequeña burguesía, gente de prensa, de radio, escritores, dirigentes sindicales, cierto tipo de trabajadores semi-proletarios." Así describe Patricio Manns a los concurrentes a la Peña de los Parra, y agrega "Sospecho que para el obrero resultábamos un grupo demasiado intelectual" (1986, p. 65). Este diagnóstico parece haber sido un elemento que no se ajustaba del todo a las necesidades que muchos artistas tenían. Así lo explicitaban los integrantes de Tiempo Nuevo, a pesar de ser un conjunto nacido de la Peña de Valparaíso, señalando que "Asistía un público bien especial, si se quiere, snob, que al fin de cuentas no sentía como propia esa música. Iban a ver algo raro, pero no suyo (Revista El Musiquero, 127, XI/1970, p. 8). 
Además de las actividades mencionadas que complementaban a la peña, Isabel y Ángel, editaron 4 LPs titulados La Peña de los Parra. Esta vertiente discográfica aportaba ingresos monetarios complementarios, pero sustancialmente ampliaba la difusión del propio local, proyectando desde la esfera pública de entretenimiento al espacio privado del consumo discográfico, "estableciendo un puente explícito entre música en vivo y sonido grabado" (GONZÁLEZ; ROLLE y OLSHEN, 2009, p. 230).

La Peña de los Parra funcionó desde su inauguración en 1965 hasta 1973, cuando la casona fue allanada, luego del golpe militar, provocando varios destrozos en las instalaciones. El grupo de artistas que habían sido animadores principales y cara visible de la peña corrieron suerte dispar luego del golpe. Patricio Manns e Isabel Parra lograron escapar del país, mientras que Ángel Parra fue detenido y pasó meses de cautiverio en durísimas condiciones. La peor parte la llevó Víctor Jara quien fue detenido horas después del golpe y al cabo de varios días de detención en el Estadio Chile fue encontrado muerto, con signos evidentes de maltrato y ensañamiento con su persona. ${ }^{5}$ Posteriormente el local fue arrendado para albergar una productora de cine y años más tarde, ya recuperada la vida democrática, se promocionó como centro cultural tratando de rescatar la figura de Violeta Parra y algo del espíritu bohemio de La Peña (GODOY, 1985). Sin embargo, la poca ayuda estatal para el sostenimiento del espacio llevó al sitio a un completo abandono. Posteriores reformas dejaron solo la fachada de la vieja casona, hasta que finalmente el 24 de abril de 2008 la ampliación de la calle Carmen obligó a demoler lo que quedaba del sitio.

\section{Imitando a los Parra}

La Peña de los Parra ejerció un importante influjo hacia aquellas manifestaciones que buscaran presentar un formato similar. Tanto es así que, en buena medida, no solamente fue la iniciadora del fenómeno sino que puede ser

\footnotetext{
${ }^{5}$ El otro integrante, Rolando Alarcón, había fallecido meses antes del golpe, de causas naturales. MAMANI, Ariel Hernán. Peñas, canción de protesta y transformación política en Chile (1965-1973). Música Popular em Revista, Campinas, ano 1, v. 2, p. 121-47, jan.-jun. 2013.
} 
considerada como el paradigma a seguir por quienes quisieran emular estos espacios artísticos.

En 1966 se vivió un clima efervescente en el ámbito universitario, lo que desembocó en la reforma universitaria impulsada por los propios estudiantes, principalmente de la Universidad Católica de Chile en el año 67. Es en esos momentos cuando las peñas se transformaron en un fenómeno difundido a lo largo de Chile. Ambos procesos guardaron puntos de contacto evidentes. La década del 60 tuvo como marca esencial el protagonismo de la juventud como agente de transformación y la música fue un espacio fundamental en este proceso en general, ya que la juventud, como grupo etáreo bien definido, estableció un nexo particular con el fenómeno musical, y en particular con la industria musical. Sin embargo las peñas, muchas de ellas motorizas por jóvenes, asumieron un importante papel en la búsqueda de alternativas a la comercialización en que caían muchas de las manifestaciones musicales. A su vez, una importante politización atravesaba a la sociedad chilena toda, y los sectores juveniles no estuvieron al margen, sino más bien todo lo contrario. Muchos jóvenes estaban deseosos de cambios importantes en la sociedad, por lo tanto el nivel de participación y discusión política fue muy alto, siendo las peñas un espacio privilegiado para fijar, al menos desde lo simbólico, una posición política o partidaria.

A partir de la experiencia de los hermanos Parra, el fenómeno de las peñas también se extendió a todo el país con extrema rapidez. En 1966 se calcula que se inauguraron cerca de 30 peñas en todo el territorio, la mayoría en Santiago (GONZÁLEZ; ROLLE, 2004).

El éxito de la Peña fue enorme y muy pronto, este tipo de espectáculos proliferó por todos lados y entró en todas las capas sociales. Se organizaron peñas en los locales sindicales, en las fábricas, en los colegios, en las poblaciones y hasta en los barrios más elegantes de las ciudades. Las peñas se impusieron como el lugar natural de la música folklórica y, durante largos años, éstas fueron la forma más regular de las presentaciones de la nueva música (SANTANDER, 1984, p. 31).

En Valparaíso un grupo de estudiantes de la carrera de Arquitectura, consiguió que la tía de uno de ellos les cediera el altillo de un restaurante en la subida Ecuador. Así nació la Peña de Valparaíso. Osvaldo Rodríguez, uno de los promotores, recuerda que “(...) el impulso vino desde Santiago, claro está, desde el 
éxito de la Peña de los Parra y el auge que comenzaba a tener la canción latinoamericana por todas partes" (1984, p. 35).

La necesidad fue la misma: lograr un espacio propio y alejado de los parámetros comerciales. El público acompañó en gran medida la propuesta, tanto que rápidamente debieron cambiarse de local ante el temor de que el pequeño espacio cediera por el peso de la concurrencia. El sótano de la propia Escuela de Arquitectura sirvió provisoriamente para alojar a la peña hasta que se trasladaron a un viejo depósito abandonado debajo de un local del Partido Radical, en la calle Blanco. Debido a las dimensiones del local, y a la disposición del escenario, en la Peña de Valparaíso se podía bailar, lo que resultó un elemento que la diferenció de las demás. “Siempre había un momento - recuerda Osvaldo Rodríguez - para hacer bailar la gente: La Nave, baile chilote, o bien bailes de la Isla de Pascua, la infaltable cueca cuando el ambiente estaba que ardía (...)" (RODRÍGUEZ, 1984, p. 36).

La peña funcionaba viernes, sábados y domingos, y como en Santiago, un grupo de músicos se presentaba regularmente. Muchos de ellos serían, con el tiempo, importantes representantes de la NCCh, como Osvaldo "Gitano" Rodríguez, "Payo" Grondona y el conjunto Tiempo Nuevo. También participaban distintos músicos invitados y, en general, todo aquél que se armara de coraje podía cantar o recitar. Allí actuaron por primera vez ante el público quienes serían uno de los grupos más importantes: Quilapayún.

Un día, terminado uno de nuestros bullados ensayos, partimos (...) decididos a dar el gran salto y, aunque no conocíamos a ninguno de los organizadores, estábamos convencidos de que nuestro canto, si en algún lugar podía comenzar a vivir, era en esa cálida covacha de poetas y nostálgicos (CARRASCO, 2003, p. 56).

Al igual que en Valparaíso, el Centro de Alumnos de la Escuela de Artes y Oficios de la Universidad Técnica del Estado (UTE) organizó su propia peña en Santiago en 1966, llamada Peña de la Federación de Estudiantes de la UTE, más conocida como Peña de la UTE. Tenía un ambiente más estudiantil aún que la de Valparaíso. Entre los organizadores estaba Horacio Durán, un joven estudiante de Ingeniería que vendía las empanadas y que a partir de allí comenzará su acercamiento a la música, convirtiéndose en algunos años en un brillante charanguista, miembro fundador de Inti Illimani, grupo señero de la NCCh. Esta 
peña funcionaba en un subsuelo de la propia Universidad cuando ya las actividades académicas habían finalizado.

Era un lugar frío y oscuro, - evoca Eduardo Carrasco - al que se llegaba atravesando los patios vacíos de la Escuela de Artes (...). Después de bajar esas desiertas escalas, para llegar por fin a la amplia sala donde tenía lugar la función, uno se sentía aliviado. En el centro, la infaltable base de madera que servía de escenario, sobre la cual se instalaba el infaltable tronco de árbol con la no menos infaltable rueda de carreta. Para qué insistir en la red de pescador del fondo o en las sillas de paja para los cantantes. Como en todas las demás peñas del país, aquí no faltaba ni la luz de las velas, ni el vino, ni las empanadas (CARRASCO, 2003, p. $58)$.

A pesar de las diferencias de ambientes, espacios $\mathrm{u}$ organizadores muchas de las peñas siguieron un mismo patrón para la decoración y se ubicaron en espacios incómodos y poco visibles, casi marginales. Al decir de Carrasco, parecía “(...) que la nueva canción había traído consigo una decoración indispensable, sin la cual era imposible concebir el espectáculo (2003, p. 58).

Allí también se instaló la discusión política pero la militancia se tornó más visible todavía, como era de esperar en un ámbito organizado por los propios estudiantes.

El anfitrión era el propio presidente del centro de alumnos, quien era el encargado de poner la nota política. De vez en cuando, entre bailes y canciones, de pronto se alternaba un discurso o una arenga llamando a los estudiantes a la concentración próxima o a la solidaridad con tal o cual urgente causa (CARRASCO, 2003, p. 58).

Estas peñas universitarias lograron un importante nivel de convocatoria imprimiendo un importante sentimiento de pertenencia a un espacio militante, tanto artístico como político, que si bien no estrictamente homogéneo, era de izquierda, pero también generacional.

Allí tuvimos nuestros primeros éxitos verdaderos, y allí también comprendimos que nuestras ideas correspondían a un espíritu generalizado en casi todas las Universidades chilenas. Nuestras canciones comenzaron a fundirse con la lucha estudiantil, y a reflejar de un modo cada vez más acertado las aspiraciones de nuestra generación (CARRASCO, 2003, p. 59).

Como se puede observar, el fenómeno de las peñas se desarrolló ampliamente en el circuito de estudiantes universitarios. En la propia Peña de los Parra, con un público muy variado, "la mayoría del público es gente joven. Da la impresión de ser estudiantes universitarios. Casi siempre terminan coreando las 
canciones que parecen conocerse de memoria" (AGUILERA, 1972, p. 26). También las sedes provinciales de la UTE organizaron sus propias peñas, siendo de importancia la de Antofagasta y la de Valdivia.

Cuando en 1968 - señala José Seves - ingresé a la UTE de Valdivia, me enteré de inmediato que había allí una peña funcionando, con local, un equipo directivo y todo. Yo comencé a cantar y me metí de lleno en la organización (...). La peña tenía una gran vitalidad. Varias veces tuvimos que cambiar de local y se hizo sin problemas. Otras peñas desaparecieron después de enfrentar dificultades similares (CIFUENTES, 2000, s/p).

En esta peña se presentaban números musicales, coreográficos, y se leía poesía. Además de los artistas locales, la mayoría de ellos vinculados al ambiente estudiantil, la peña enviaba a Santiago un emisario para contratar artistas más reconocidos, como Patricio Manns, Margot Loyola o Inti Illimani. Los estudiantes, además, lograron establecer una interesante red de actividades que no se circunscribían únicamente al ámbito específico de la peña folclórica. La peña contaba con espacio radial en los programas de la emisora de la UTE y los estudiantes

Participábamos también - rememora Seves - en las Escuelas de Temporada de la UTE, dando clases de guitarra y danza. Así fuimos al extremo Sur de Chile, a Aysén y Magallanes. La Universidad siempre nos integró a sus actividades extramurales, con lo que también demostraba una valoración por nuestro trabajo (CIFUENTES, 2000, s/p).

Es así como la Peña de la UTE de Valdivia se transformó en un importante polo de irradiación cultural, excediendo el marco meramente universitario y llevando sus actividades hacia otros sectores de la sociedad.

(...) debo indicar - enfatiza Seves - que en Valdivia yo tuve mi primer contacto directo con la izquierda organizada. Yo en ese tiempo no pertenecía a ninguna organización, pero veía como los jóvenes de izquierda participaban con entusiasmo en las actividades gremiales y culturales (CIFUENTES, 2000, s/p).

En el n 40 de la calle Dardignac, en Santiago, desde 1966 también funcionó una peña estudiantil de la FESES (Federación de Estudiantes Secundarios de Santiago), cuyos estudiantes no quisieron quedar fuera de esa moda militante y musical, con la característica que en ella se interpretaba música de diversos géneros y estilos, no solamente folklore y canción protesta (CIFUENTES, 2000, s/p). 


\section{Para reír y cantar}

A su regreso de México en 1963 René Largo Farías, personaje ligado a la radiofonía, llevó adelante en Radio Minería un programa denominado Chile Ríe y Canta. El programa estaba basado en presentaciones en vivo de artistas folclóricos, tratando de rescatar no sólo el folclore de Chile, sino también un formato a punto de extinguirse: el show radial con música en vivo. Al año siguiente el programa comenzó a presentarse como espectáculo itinerante abarcando toda la geografía de Chile (GONZÁLEZ; ROLLE; OLSHEN, 2009). La experiencia contó con el apoyo del Instituto de Desarrollo Agropecuario, como una actividad de extensión, en momentos en que el gobierno democristiano de Frei intentaba llevar adelante la reforma agraria. Sin embargo, a pesar de haber realizado varias giras, la posterior pérdida del apoyo estatal hizo decaer el proyecto. La respuesta de Largo Farías fue la fundación de una peña, hacia 1967, denominada de la misma manera, ubicada en Alonso Ovalle 755, en Santiago, a pocas calles de la Peña de los Parra.

Es un gran caserón, con una entrada amplia (donde una foto de Violeta da la bienvenida) y un bar con su correspondiente mesón. En el patio cubierto funciona la peña. El lugar está lleno de luz y los garzones andan rápido entre las mesas, atendiendo a los clientes (AGUILERA, 1972, p. 26).

A diferencia de la Peña de los Parra, en este local "El público es más adulto y parecen predominar los matrimonios o grupos familiares" (Revista Ramona 32, VI/1972, p. 17). Sin embargo había un aire compartido entre ambos sitios. Muchos artistas se presentaban tanto en una como otra peña manteniendo el perfil comprometido políticamente. Pero a pesar de estas similitudes, el aire menos bohemio de Chile Ríe y Canta permitió llegar a sectores a los que el local de los Parra no había logrado seducir. Tito Fernández, músico que actuó en ambos locales sostiene que a la peña de Largo Farías "Iba gente más obrera, más de pueblo. Esa gente no iba a la 'Peña de los Parra'”' (BRAVO; GONZÁLEZ, 2009, p. 34).

La Peña Chile Ríe y Canta formaba parte de un amplio desarrollo cultural, que además del susodicho local y su espacio radial, funcionó a modo de embajada itinerante de la música chilena por todo el territorio, ya que las giras continuaron 
pero con formato diferente. De esta manera se recorrieron hasta los poblados más pequeños y se permitió la cohabitación en esas giras de exponentes de las distintas vertientes del canto popular (SANHUEZA, 2006). Además, a través de este espacio, se intentó crear una asociación sindical de artistas folclóricos, lo que mostraba su vocación, similar a los Parra, de trascender lo meramente musical.

También actuó allí un grupo de artistas más o menos estables (en la llamada "Peña Grande"), pero al finalizar las funciones había espacio para que cualquier aficionado o novel artista pudiese mostrar su trabajo. “(..) aparece algún joven que realmente gusta, los artistas de 'Chile Ríe y Canta' lo incentivan, lo ayudan a superar sus errores y lo presentan posteriormente en la 'peña grande'" (Revista Ramona 32, junio 1972, p. 17).

Al igual que los Parra, parte de las ganancias se repartían entre los músicos participantes. Sin embargo el local tenía un tinte más comercial. Uno de los administradores del espacio explicaba al respecto “(...) que antes se preocupaban demasiado de la parte folklórica y que esto les dejaba pérdidas, así es que se vieron en la necesidad de darle mayor importancia a lo comercial, sin dejar de lado la difusión de la música" (AGUILERA, 1972, p. 27). A pesar de ello, esta peña, al igual que el local de los Parra, poseía una clara orientación en cuanto a lo ideológico que atraía a determinado tipo de público, ávido de novedades en lo musical pero comprometido políticamente.

Los estudiantes que asisten habitualmente se pelean los sectores que atiende Don Goyo. (...) Generalmente se acerca a Cristina (la compañera de René Largo Farías), quien administra el local, y le dice tímidamente: 'Hay un grupo de estudiantes, parece que son de la Jota [Juventud Comunista] y tienen poca plata. ¿Por qué no le hacemos un medio asadito?' (Revista Ramona 32, junio 1972, p. 17).

Entre los platos se destacaba el "plato único", que consistía en una porción de papas fritas con carne picada que resultaba suficiente para paliar el hambre de los nutridos grupos de jóvenes militantes con escasez de dinero.

La dictadura golpeó fuerte también a este espacio, que fue allanado y clausurado. René Largo Farías se exilió en México. 


\section{Otras peñas, otras ideas}

Habría que decir que los concurrentes se identificaban con estos sitios, que por su funcionamiento, decoración, oferta culinaria y repertorio que allí se ejecutaba, establecían un perfil determinado donde se podían reflejar sectores de izquierda. No obstante, La Peña de los Parra logró conformar una identidad que se transformó en un modelo a seguir, no solamente por sus imitadores sino también por aquellos que, aún participando de espacios con características similares, se presentaban como detractores de aquella, quienes no titubeaban en presentar a sus peñas como alternativas al modelo de los Parra, ora desde lo artístico, ora desde lo ideológico.

Es por eso que a pesar de tener una influencia importante en el surgimiento y desarrollo de estos espacios, el público cercano a los ideales de la izquierda no fue el único que se acercó a las peñas. Conjuntamente a los estudiantes y de los sectores con inclinaciones políticas y culturales (y a los turistas, los snobs y los aventureros sin ideologías), parecía haber un público también ávido de este tipo de espacios, que no debe circunscribirse únicamente a los sectores descriptos. De manera que el "boom" de las peñas influyó también sobre las imágenes folclóricas más tradicionales y en sus cultores.

En 1965, la reconocida recopiladora de folclore Margot Loyola, abrió su propia peña en Santiago. Se denominó La Chingana y funcionó en la Casa de la Cultura Folklórica, en la calle Huérfanos 540 (GONZÁLEZ; ROLLE; OLSHEN, 2009). El propio nombre de la peña implicó una especie de reconocimiento a las chinganas del siglo XIX. Estos eran sitios donde se bebía, se bailaba y se cantaba música tradicional. De esa forma se explicitaba que este tipo de reuniones no eran un invento parisino exportado por los Parra, sino que poseían, aún con grandes diferencias, una tradición vernácula que merecía ser rescatada.

El reconocido folclorista Chito Faró también impulsó su propio local en Santiago, pero con características más comerciales y donde se jactaba cultivar un folclore supuestamente más "auténtico" y no comprometido políticamente. Por ello declaraba ante la prensa: "Esta es la única peña de Santiago donde no se admiten melenudos ni se cantan las estúpidas canciones de protesta" (LARGO FARÍAS, 1977, 
p. 18). Faró, seudónimo de Enrique Motto Arenas, como muchos otros folcloristas había logrado insertarse en algunos espacios, como por ejemplo las boites, donde alcanzó una moderada presencia en las década del 50 y principios de los 60 (GONZÁLEZ; ROLLE; OLSHEN, 2009), sin embargo las peñas parecían un espacio mucho más acorde a este tipo de manifestaciones.

Otro importante espacio fue El Alero de Los de Ramón. Esta peña se diferenciaba bastante del estereotipo universitario o cooperativo. Ya su ubicación presentaba diferencias: se encontraba en una zona alejada del centro de la ciudad, en la Comuna de Las Condes, un tramo un tanto periférico por aquél entonces cuya urbanización estaba asociada a sectores sociales altos. La peña, por ejemplo, contaba con una fracción de terreno dedicada al estacionamiento de automóviles, supervisado además por un cuidador, lo que demuestra el tipo de clientela que allí frecuentaba.

(...) observábamos -escribe el cronista de la revista Ramona- la decoración de ese restaurante folklórico de Las Condes. Parecía que hubiésemos retrocedido en el tiempo, llegando a la mansión de una familia de la alta aristocracia colonial. Rápidamente volvimos a la realidad y nos dimos cuenta que sólo habíamos recorrido un par de kilómetros (...) donde la alta burguesía que aún existe en nuestro país gasta unos cuantos billetitos azules para divertirse un poco" (Revista Ramona 32, junio 1972, p. 14).

En la cita precedente notamos como el cronista denomina a este sitio como un "restaurante folclórico", haciendo notar la diferencia existente con las otros espacios descriptos en la crónica.

En principio el Alero debía ser un centro de la chilenidad. Pero como eso no daba plata, Los de Ramón decidieron cambiar de idea. Crearon un lujoso restaurante con un toque folklórico (...) (Revista Ramona 32, junio 1972, p. 14).

El público asistente parece haber sido muy diferente a varios de los ejemplos anteriores. Ya por su vestimenta se podía vislumbrar: "trajes largos, elegantes para ellas, y tenida de etiqueta para ellos" (AGUILERA, 1972, p. 27). También se diferenciaba de alguno de los espacios antes mencionados en el costo que tenía asistir al Alero. El cronista de Ramona agrega que al observar los precios de la carta se le había quitado el apetito, calculando que se necesitaban, al menos, $\mathrm{E}^{\mathrm{o}} 250$ por persona para cenar. Mientras que en la Peña Chile Ríe y Canta “¡Grata sorpresa! 
con $\mathrm{E}^{\mathrm{o}} 50$ se puede comer, tomar, cantar y bailar hasta que las velas no ardan" (Revista Ramona 32, junio 1972, p. 15).

Sin embargo el contraste de estos espacios con las peñas descriptas anteriormente no residía solamente en el poder adquisitivo de los asistentes ni en la orientación política o artística de los músicos que allí actuaban. Cada uno de ellos representaba ámbitos de sociabilidad diferentes, donde lo que se consumía, lo que se escuchaba, o como se decoraba el lugar, eran indicios fuertes acerca de la posición política que, eventualmente, podrían tomar.

\section{Palabras finales}

Es posible establecer una relación entre espacio, repertorio y función social de la música. Este vínculo siempre estuvo de alguna forma presente y se hace evidente si se toma como ejemplo una marcha militar, una música religiosa o una fanfarria de palacio. Sin embargo la influencia portentosa de la industria musical logró llevar al hogar cualquier clase de música, logrando así desvincular la función social original de determinados tipos de música. No obstante, como afirman Rolle y González, diversos ejemplos en la música popular lograron establecer una clara asociación entre espacio y género musical, donde "una suma de elementos arquitectónicos y escenográficos parecen contribuir a completar el sentido de la música" (2004, p. 271). Es así como la condición que le otorga la reproductibilidad técnica y el acceso doméstico a diversos tipos de música fue borrando un poco dichos límites, permitiendo el goce de fenómenos musicales en interacción entre ámbito privado y espacio público. En este sentido se puede argumentar que las peñas, en especial aquellas vinculadas a un determinado espectro ideológico y estético cercano a la izquierda, fueron sitios donde constantemente se producía dicha interacción. La peña, como parte de un espacio no privado, tenía dimensiones reducidas, lo que brindaba cercanía entre intérprete y público. A su vez lo despojado de la performance y el alejamiento de las ataduras comerciales le otorgaban un carácter intimista, ligándolo de hecho a una imitación, en cierto sentido, del ámbito privado. 
En este trabajo hemos observado como en pequeños y lúgubres locales se daban cita un heterogéneo grupo de personas que, iluminados por una vela o al calor de un brasero, participaban del hecho artístico de la interpretación musical y poética, compartiendo un espacio altamente politizado, donde la cultura de izquierda mantuvo un papel cardinal. También observamos como espacios similares, con otra orientación y decoración, representaban un paradigma bien diferenciado, más cercano a los estereotipos que habían dominado por largo tiempo en la música de raíz folclórica. En definitiva, la emergencia del fenómeno de las peñas es uno de los indicadores más fuertes de la tensión existente entre dos sectores de la música popular chilena a mediados de la década de los 60. En este sentido, las peñas, bien como motorizadores de un cambio en el paradigma estético e ideológico de la música de raíz folklórica, o bien como reservorio último de la tradición, se transformaron en piezas esenciales de esa confrontación.

Algunas peñas tuvieron una existencia efímera y diletante, otras permanecieron por largo tiempo, logrando transformarse en emblemas importantes de la cultura y la política. Puede decirse que la Peña de los Parra fue el espacio pionero. Pudo fijar un modelo muchas veces imitado, y muchas veces también criticado. Lo cierto es que no pasó desapercibido a propios ni extraños, estableciendo un ámbito de sociabilidad en el espacio urbano que logró permanecer por varios años, y que no solo fue un lugar alternativo para la difusión de la música popular chilena y latinoamericana, sino que se transformó en un ámbito propicio para la identificación política, estableciendo un parámetro importante para el reconocimiento identitario de muchas personas. La Peña de los Parra puede ser considerada como un arquetipo de este tipo de reuniones. Su decoración, funcionamiento interno y repertorio musical, conformó una identidad que logró establecer cierto modelo a imitar, tanto por sus seguidores como por sus detractores, quienes no dudaban en presentar a sus propios espacios como alternativos al local de los Parra.

De todas maneras, a pesar de la constante asistencia de público y los resultados alcanzados, las peñas no fueron espacios de masividad sino que continuaron ejerciendo atracción para un grupo reducido. 
La década del 60 tuvo como marca esencial el protagonismo de la juventud como agente de transformación y la música fue un espacio fundamental en este proceso en general. De todas maneras las peñas asumieron un importante papel en la búsqueda de alternativas a la comercialización en que caían muchas de las manifestaciones musicales orientadas a la juventud.

Las peñas fueron esenciales, por otro lado, en la formación de gustos musicales, como así también en la instalación de nuevas formas de consumo musical en determinados sectores urbanos. A su vez este fenómeno de ampliación del público estimuló un interesante grado de divulgación, esencial para el espectro musical e ideológico que adolecía de espacios en los medios masivos. Es posible argumentar que las peñas fueron un importante medio de difusión con la que contó el movimiento de la NCCh, especialmente en sus primeros años, constituyendo la primera manifestación del sistema de difusión de la NCCh (GONZÁLEZ; ROLLE; OLSHEN, 2009).

Además las peñas, al menos aquellas donde el repertorio y los artistas convocaban a un público simpatizante de izquierda, fueron un ámbito de reunión que permitió asumir un sistema de valores en buena mediada compartidos. Este mutuo reconocimiento entre los concurrentes podía también darse, con otras características, tanto en el sindicato, la universidad, la junta barrial o en un acto partidario. Sin embargo, y pese a ello, al realizarse en un ámbito desestructurado donde el entretenimiento y el goce estético se presentaban como los objetivos inmediatos, la empatía entre artistas, obra musical y auditorio generó un núcleo de fuerte contenido comunicativo que difícilmente se hubiera logrado de manera tan contundente en otros ámbitos. La audición musical, el intercambio de ideas y la conversación animada ofrecieron a los asistentes un conjunto de elementos más que atrayente para aquellos sectores deseosos de los debates políticos y abiertos a la renovación musical.

Estos espacios, en definitiva, fueron una esfera de capital importancia para la consolidación de la canción de protesta, encarnada principalmente en la NCCh, pero también fue un importantísimo ámbito de socialización de sectores vinculados a la izquierda chilena. Allí la música era la excusa principal para quienes buscaban un 
acercamiento al arte por fuera de las formas comerciales y cuyo contenido favoreciera la discusión política e ideológica en un ambiente bohemio por antonomasia.

\section{Referencias bibliográficas}

ADVIS, Luis. Historia y características de la Nueva Canción Chilena. en ADVIS, Luis; GONZÁLEZ, Juan Pablo; CÁCERES Eduardo y GARCÍA Fernando (eds.). Clásicos de la Música Popular Chilena, Vol. 2 1960-1973. Santiago: SDC, 2012, pp. 30-41.

AGUILERA, Pablo. La peñas folclóricas: ¿negocio o difusión? Revista Onda, Santiago, n²7, sep. 1972.

BRAVO, Gabriela y GONZÁLEZ, Cristian. Ecos del tiempo subterráneo. Las peñas en Santiago durante el régimen militar (1973-1983). Santiago: Lom, 2009.

CARRASCO, Eduardo. Quilapayún, la revolución y las estrellas. Santiago: Ril, 2003.

CIFUENTES, Luis. Fragmento de un sueño. 2000. Disponible en: http://www.cancioneros.com/co/3719/2/fragmentos-de-un-sueno

COLLIER, Simon. Chile. En Bethell, Leslie (ed) Historia de América Latina vol. 9, Barcelona: Crítica, pp. 238-273.

COSTA GARCÍA, Tânia da. Canción popular, nacionalismo, consumo y política en Chile entre los años 40 y 60. Revista Musical Chilena, Santiago, Año LXIII, n 212, 2009, pp 11-28.

GODOY, Álvaro. La Peña de los Parra: donde se quedó el canto. La Bicicleta. Santiago, Año VII, nº62, Agosto 1985.

GONZÁLEZ, Juan Pablo; ROLLE, Claudio y OLSHEN, Oscar. Historia social de la música popular en Chile, 1950-1970. Santiago: Ediciones de la Universidad Católica de Chile, 2009.

GONZÁLEZ, Juan Pablo; ROLLE, Claudio. Historia social de la música popular en Chile, 1890-1950. Santiago: Ediciones de la Universidad Católica de Chile, 2004.

JARA, Joan. Víctor un canto inconcluso. Santiago: Lom, 2009.

LARGO FARÍAS, René. La Nueva Canción Chilena. México: Casa de Chile, 1977.

MANNS, Patricio. Violeta Parra, la guitarra indócil. Concepción: Ediciones LAR, 1986.

OVIEDO, Carmen. Mentira todo lo cierto: Tras la huella de Violeta Parra. Santiago: Editorial Universitaria, 1991. 
Revista Ecran, n 1876, Santiago: 17 enero 1967.

Revista Ramona, n 32, Santiago: Junio 1972.

RIMBOT, Emmanuelle. Autorrepresentación y manifiesto en la Nueva Canción y Canto Nuevo. En Revista Cátedra de Artes. Santiago, No 3, Segundo semestre de 2006.

RODRÍGUEZ, Osvaldo. Cantores que reflexiona. Notas para una historia personal de la Nueva Canción Chilena. Santiago: LAR, 1984.

SALAS ZÚÑIGA, Fabio. La primavera terrestre. Cartografias del Rock Chileno y la Nueva Canción Chilena. Santiago: Cuarto Propio, 2003.

SANHUEZA, César. No hay revolución sin canciones, auge y quiebre de la nueva canción chilena 1969-1973. Tesis de Licenciatura inédita, Santiago, Universidad Católica, 2006.

SANTANDER, Ignacio (Eduardo Carrasco). Quilapayún. Barcelona: Ediciones Júcar, 1984.

VARAS, José Miguel; GONZÁLEZ, Juan Pablo. En busca de la música chilena: crónica y antología de una historia sonora, Volumen 1. Santiago: Cuadernos Bicentenario, 2005. 